\title{
Knowledge attitude and practice of breast self examination among female medical students in a medical college
}

\author{
Velayuthan C.K. ${ }^{1}$, Gopinath V. ${ }^{2}$ \\ ${ }^{1}$ Dr. C.K. Velayuthan Nair, Professor, ${ }^{2}$ Dr. Vinu Gopinath, Assistant Professor; both authors are attached with Department of \\ General Surgery, Sree Mookambika Institute of Medical Sciences, Kulasekharam, India
}

Address for Correspondence: Vishnu. G. Ashok, Assistant Professor, Department of Community Medicine, Sree Mookambika Institute of Medical Sciences Kulasekhram. E-mail: vishnusastha@gmail.com

\begin{abstract}
Background: Breast cancer is the most prevalent type of cancer in women both in high income and in low- middle income countries. The incidence of breast cancer is increasing in low and middle income countries. Breast self examination, Clinical breast examination and mammography are the preventive technique to reduce breast cancer mortality. Out of this breast self examination is an inexpensive tool that can be carried out by women themselves. Aims \& Objectives: To assess the Knowledge, Attitude and Practice regarding breast self examination among female medical students. Subjects and Methods: The study was conducted at Outpatient department of, General surgery in Sree Mookambika Institute of Medical Sciences, Kulasekharam. It is a cross sectional study where all females belong to Final year medical students and interns were included. The study involved administration of pretested questionnaire. Results: $96 \%$ of the respondents replied that breast self examination helps in early diagnosis of breast cancer, $89 \%$ have the opinion that breast self examination is essential. Conclusion: The Knowledge about Breast self examination is good among the medical students and that they know that it is essential to perform BSE regularly.
\end{abstract}

Key words: Breast self examination (BSE), Medical students, Females

\section{Introduction}

Breast cancer is the most prevalent type of cancer in women both in high income and in low- middle income countries [1]. WHO predicted that in 2015, 155863 new cases will be detected in India and there will be 75957 deaths due to breast cancer in India in 2015[2]. The incidence of breast cancer is increasing in low and middle income countries because of increased life expectancy, urbanization and adoption of western lifestyles [1]. Breast cancer is distinguished from other types of cancer by the fact that it occurs in a visible organ and be detected and treated at an early stage [3]. The 5-year survival rate reached to $85 \%$ with early detection whereas later detection decreased the survival rate to $56 \%$ [4]. In the literature, it is stated that $90 \%$ of the times breast cancer is first noticed by the person herself [5].

Recommended preventive techniques to reduce breast cancer mortality and morbidity include breast self examination (BSE), clinical breast examination (CBE), and mammography [6]. Clinical breast examination and

Manuscript Received: 06 ${ }^{\text {th }}$ December 2016

Reviewed: $14^{\text {th }}$ December 2016

Author Corrected: $20^{\text {th }}$ December 2016

Accepted for Publication: $31^{\text {st }}$ December 2016 mammography require hospital visit and specialized equipment and expertise whereas breast self examination is an inexpensive tool that can be carried out by women themselves. Breast self examination benefits women in two ways: women become familiar with both the appearance and the feel of their breast and detect any changes in their breasts as early as possible [7]. Also, several studies have shown that barriers to diagnosis and treatment can be addressed by increasing women's awareness of breast cancer [8].

Several reasons like lack of time, lack of self-confidence in their ability to perform the technique correctly, fear of possible discovery of a lump, and embarrassment associated with manipulation of the breast have been cited as reasons for not practicing breast self examination [9]. Raising the awareness about breast self examination is very important because an excellent prognosis is directly associated with the detection at the early stage. With this background, the present study was designed to determine the knowledge, attitude, and practice (KAP) regarding breast self examination in a cohort of Indian female medical students. 


\section{Aims \& Objectives}

To assess the Knowledge, Attitude and Practice regarding breast self examination among female medical students.

\section{Materials and Methods}

a) Study design: Cross sectional Study

b) Study setting: Outpatient department of, General Surgery Sree Mookambika Institute Of Medical Science, Kulasekharam.

c) Approximate total duration of the study: 8months(April 2015-December 2015)

d) Detailed description of the groups: All final year female medical students and female interns of Sree Mookambika Institute of Medical Sciences

\section{e) Total sample size of the study: 100}

f) Scientific basis of sample size used in the study: All females belong to final year MBBS and Interns were included so no sample size

g) Inclusion criteria/ exclusion criteria: Those who are not willing

h) Parameters to be studied: Knowledge attitude and practice regarding breast self examination

i) Methods(s)/Technique(s)/Reagent(s)/Kit(s) etc. used to measure the qualitative parameters along with their manufacturing source details: Pretested questionnaire was applied

j) Procedure: After getting approval from Institutional Human Ethical Committee written informed consent was obtained from the participants before enrolling them into study. Pretested questionnaire was applied by the chief investigator

\section{Results}

Knowledge: $99 \%$ of the participants know that early detection increases the chance of survival of breast cancer. $96 \%$ of them replied that BSE helps in early diagnosis of breast cancer, highest knowledge score was found for these questions. Only 57\% of the respondents know that the recommended frequency of doing BSE is monthly. $68 \%$ of respondents know that BSE should be started from the end of teen age. Only $73 \%$ knows that the correct time of doing BSE after menstruation. $64 \%$ of the respondents know that $\mathrm{BSE}$ should be done in front of mirror and $54 \%$ know that it can be done in supine position. Only $18 \%$ of the respondents were aware that patients with breast implants can also perform BSE. The lowest knowledge score was found for this. $74 \%$ of the participants have good knowledge regarding breast self examination while $20 \%$ has very good knowledge and $6 \%$ has poor knowledge.

Attitude: $97 \%$ of the respondents think that breast self examination is absolutely necessary. $89 \%$ have the opinion that breast self examination is essential and $10 \%$ think that it is moderately useful. $9 \%$ have the opinion that breast self examination is essential and $10 \%$ think that it is moderately useful and $1 \%$ think that it is minimally useful. $58 \%$ of the respondents have done breast self examination before and $42 \%$ have not it before yet. Only $23 \%$ of the respondents said that they were regularly performing breast self examination, and the remaining $77 \%$ were not regular in performing breast self examination.

Practice: Of the respondents who were performing BSE majority of the $(95 \%)$ started it above the age of 19 , and $5 \%$ of the started it before the age of 19 . Only $18 \%$ of them were doing BSE on a regular day of the month, remaining $82 \%$ were doing it on any day of the month. $23 \%$ of the respondents were performing BSE monthly, $9 \%$ of them are performing weekly and $26 \%$ were not performing frequently and $42 \%$ have not done it.

\section{Discussion}

In our study, almost everyone (99\%) know that early detection increases the chance of survival of breast cancer whereas $87.5 \%$ know it among the nursing students in Puducheri [10]. In our study $96 \%$ said that BSE helps in early diagnosis of breast cancer whereas $89.2 \%$ among nursing students in Puducheri [10] and Peter et al [11] found that $88.6 \%$ of female undergraduate students only know about it. $57 \%$ of female medical students know that BSE should be done monthly, whereas $50.4 \%$ and only $37.3 \%$ knows among nursing students [10] and female undergraduate students [11].

In our study $68 \%$ of female medical students know that breast self examination should be started at teen whereas only $47.5 \%$ knows among nursing students. [10]. $73 \%$ of female medical students know that breast self examination should be done after menstruation, whereas only $66.4 \%$ knows among female health workers [12]. Overall studies among medical and paramedical population have higher knowledge score than studies among general population. In our study $97 \%$ know that breast self examination is necessary whereas it is $93.3 \%$ among nursing students [11]. In our study $89 \%$ opine that breast self examination 
is essential whereas it is $34.4 \%$ among female undergraduates [11]. $31 \%$ of our study population said that they felt embarrassed doing breast self examination compared to $4.8 \%$ in nursing students. So the general attitude towards BSE in our study is good compared to other studies. But there is a higher percentage of women feeling embarrassed doing breast self examination in our study than the studies conducted among western population. Only $58 \%$ have done BSE before but is 87.5 $\%$ among study done by sujindra et al10]. and $29.5 \%$ in female undergraduates [11].

In our study $23 \%$ are regularly performing breast self examination whereas $33.3 \%$ among nursing students [10] and only $3 \%$ in female undergraduates [11]. Practice of breast self examination is high in our study than general population studies as $58 \%$ have already done breast self examination in our study. But the practice is still higher among nursing population with the fact that only $23 \%$ are regularly performing breast self examination in our study compared to $33 \%$ among nursing students [10]. Among those who perform breast self examination, most of them $(95 \%)$ in our study had started performing before the age of 19 years in contrast to the nursing students most of them $(65.8 \%)$ had started performing it after the age of 19[10]. This may be attributed to the introduction of breast self examination in the first year of medical curriculum around the age of 18 .

The level of practice of breast self examination in our study is low as evidenced by the fact that most of them are performing it on any day of the month $(82 \%)$ as opposed to the correct way of performing which is on a fixed day of each month. In our study $23 \%$ of those who are performing BSE are doing it monthly whereas $39.5 \%$ among female health workers [12]. So the levels of practice in our study lower than study among female heathworkers $^{12}$ but higher than studies in general population [13]. Our study showed that female medical students had overall high knowledge than similar studies conducted among general population. But female health workers [11] $(80 \%)$ have a better knowledge score than the female medical students $(74 \%)$ as per the studies. This may be due BSE occupying a small part of the vast curriculum of medical students whereas health workers are involved in active health education programes

Conclusion \& Recommendations- From our study, The Knowledge about Breast self examination is good among the medical students and that they know that it is essential to perform BSE regularly. But the initiation and continuance of the practice of breast self examination is minimal. For this, counseling sessions to motivate the initiation and the continuance of BSE could be conducted in the respective General surgery posting of the students. The importance could be highlighted and its cost effectiveness can be told

Funding: Nil, Conflict of interest: None initiated, Permission from IRB: Yes

\section{References}

1. WHO (2014). Breast cancer: prevention and control. Retrieved at http://www.who.int/cancer/detection/breastcancer/en/inde x3.html; accessed12 May 2015

2. Breast cancer epidemeiology.retrieved athttp://www.breastcancerindia.net/satistics/statglobal.html;accessed on 17 may 2015

3. Tasci A, Usta YY. Comparison of Knowledge and Practices of Breast Self Examination (BSE): A Pilot Study in Turkey. Asian Pac J Cancer Prev. 2010;11(5):1417-20.

4. Hallal JC. The relationship of health beliefs, health locus of control, and self concept to the practice of breast self-examination in adult women. Nurs Res. 1982 MayJun;31(3):137-42.

5. Simsek S, Tug T. Benign tumors of the breast: fibroadenoms. Sted, 2002; 11: 102-105

6. Humphrey LL, Helfand M, Chan BK, Woolf SH. Breast cancer screening: A summary of the evidence for the U.S. Preventive Services Task Force. Ann Intern Med. 2002 Sep 3;137(5 Part 1):347-60.

7. Karayurt O, Ozmen D, Cetinkaya AC. Awareness of breast cancer risk factors and practice of breast self examination among high school students in Turkey. BMC Public Health. 2008 Oct 17;8:359. doi: 10.1186/14712458-8-359.

8. Doshi D, Reddy BS, Kulkarni S, Karunakar P. Breast Self-examination: Knowledge, Attitude, and Practice among Female Dental Students in Hyderabad City, India. Indian Journal of Palliative Care. 2012;18(1):68-73. doi:10.4103/0973-1075.97476.

9. American Cancer Society (2014). American Cancer Society recommendations for early breast cancer detection in women without breast symptoms. Retrieved at http://www.cancer.org/cancer/breastcancer/moreinformati on/breastcancerearlydetection/breast-cancer-earlydetectionacs-recs; accessed 12 May 2014.

10. Sujindra E, Elamurugan TP. Knowledge, attitude, and practice of breast self-examination in female nursing 


\section{Research Article}

students at puducheri india. Int J Educ Psychol Res 2015;1:71-4.

11. Nde FP, Assob JCN, Kwenti TE, Njunda AL, Tainenbe TRG. Knowledge, attitude and practice of breast self-examination among female undergraduate students in the University of Buea. BMC Research Notes. 2015;8:43. doi:10.1186/s13104-015-1004-4.

12. Reisi M, Javadzade SH, Sharifirad G. Knowledge, attitudes, and practice of breast self-examination among female health workers in Isfahan, Iran. Journal of Education and Health Promotion. 2013;2:46. doi:10.4103/2277-9531.117417.

13. Gupta SK etal study on Impact of a health education intervention program regarding breast self examination by women in a semi-urban area of Madhya Pradesh, India. Asian Pac J Cancer Prev. 2009;10(6):1113-7.

\section{How to cite this article?}

Velayuthan C.K., Gopinath V. Knowledge attitude and practice of breast self examination among female medical students in a medical college. Int J surg Orthopedics 2016;2(4):67-70.doi:10.17511/ijoso.2016.i4.03. 